\title{
Microvascular complications in type 2 diabetes and associated factors: a telephone survey of self-reported morbidity
}

\author{
Aliny de Lima Santos ${ }^{1}$ \\ Hellen Pollyanna Mantelo Cecílio ${ }^{1}$ \\ Elen Ferraz Teston ${ }^{1}$ \\ Guilherme Oliveira de Arruda ${ }^{1}$ \\ Fabiana Magalhães Navarro Peternella ${ }^{1}$ \\ Sonia Silva Marcon ${ }^{1}$
}

${ }^{1}$ Pós-Graduação em Enfermagem, Centro de Ciências da Saúde, Universidade Estadual de Maringá. Av. Colombo 5790, Jardim Universitário. 87020-900 Maringá Paraná Brasil. aliny.lima.santos@ gmail.com

\begin{abstract}
The scope of this article is to estimate the prevalence of microvascular complications of self-reported type 2 diabetes and the association with sociodemographic characteristics, nutritional status, treatment given and time since diagnosis. It involved a cross-sectional study with 318 people with type 2 diabetes living in Maringá in the State of Paraná. A telephone survey of self-reported morbidity was conducted in the months from January to June 2012. For the analysis descriptive statistics, univariate and multiple logistic regression were used. The prevalence of self-reported complications of diabetes was $53.8 \%$, the most frequent being retinopathy (42.8\%), followed by peripheral neuropathy (14.5\%) and nephropathy (12.9\%). The variables associated with the presence of complications were age ( $p=$ $0.008)$, overweight/obesity ( $p=0.002)$, insulin ( $p$ $<0.001)$, insulin use linked to oral antidiabetic drug $(p=0.003)$ and time since diagnosis ( $p=$ 0.013). The prevalence of self-reported microvascular complications for people with diabetes was high, being more frequent among those of more advanced age, with inadequate nutritional status, a delay in diagnosis of the disease and those who were using insulin alone or in combination with oral antidiabetic agents.
\end{abstract}

Key words Diabetes mellitus, Complications of diabetes, Cross-sectional studies, Prevalence 


\section{Introduction}

Type 2 diabetes mellitus ('DM2'), like other chronic diseases, is considered to be a public health problem, not only in developed countries, but also in developing countries ${ }^{1}$. It is a health condition with high rates of occurrence of illness and mortality - currently affecting more than $20 \%$ of adults between the ages of 65 and $76^{2}$.

It is estimated that by 2030,366 million people in the world will have diabetes. In Brazil, the number of people suffering will increase from 4.5 million (in 2000) to 11.3 million, resulting in the country having, by that date, the eighth highest rate of occurrence of the disease worldwide ${ }^{3}$. DM2 is the most common form of the disease approximately $90 \%$ of cases - and its emergence has an intimate relationship with inappropriate lifestyle habits, which compromise the action and production of insulin, or cause a predisposition to resistance to insulin ${ }^{4}$.

In initial stages, the illness can be oligosymptomatic or even asymptomatic. This can delay its diagnosis, increasing the risk of complications that can be acute - including hypoglycemia, diabetic ketoacidosis and hyperosmolar coma - or chronic, such as micro- and microvascular alterations.

In relation to the chronic complications, there is the distinction between macrovascular and microvascular. Examples of macrovascular complications would include ischemic cardiomyopathy, cerebrovascular disease, and peripheral vascular disease, all frequently associated with the disease and possibly leading to death ${ }^{5,6}$. Microvascular complications are characterized by damage to vision (retinopathy), kidney disease (nephropathy) and neurological lesions (neuropathy). These are the most common causes of irreversible blindness, chronic kidney disease and non-traumatic leg amputations $s^{5,7,8}$.

The chronic complications of DM2 are some of the principal causes of illness and mortality, and a source of growing concern for health authorities in developed countries ${ }^{5}$. It is thus important for health professionals to know the factors that predispose a person to occurrence of chronic microvascular complications. Among these factors, the literature highlights the importance of (i) the type of treatment, (ii) the time elapsed since discovery of the diagnosis, and (iii) the patient's nutritional state ${ }^{9}$. Aware of the social-demographic characteristics commonly associated with the appearance of complications is also important for choosing a direction for im- plementation of actions with patients suffering from diabetes.

On this subject, Brazilian studies on the occurrence of microvascular complications of diabetes, and the social-demographic factors associated with those complications, have been made in various capital cities of Brazil's states ${ }^{5,8,10,11}$, and they have discovered differences in and relating to the complications affecting the population concerned. However, there is little information available about the percentage of occurrence, and factors associated with the microvascular complications of DM2, in the state of Paraná, indicating a need for investigation on the subject.

Telephone surveys can be an effective strategy for monitoring and control of risk factors for complications. Studies that use this strategy can serve to indicate percentage of occurrence of these risk factors, and also of the complications that are present in people with DM2. This type of contact also has the advantage of being viable in financial and logistical terms, and can have a positive influence on the self-care of a person with diabetes, especially in the ambit of primary healthcare ${ }^{12}$. However, studies using this method are still rare in Brazil, and as far as is known non-existent in the state of Paraná.

It is considered that production of information on percentage of occurrence, and the factors associated with microvascular complications, in general and in specific regions, can broaden knowledge on the health profile of people with DM2, and can favor formulation of feasible policies and strategies for prevention and treatment of the condition. With this in mind, the aim of this study has been to determine the levels of occurrence of self-reported microvascular complications from Type 2 diabetes mellitus, and ascertain the associations with social-demographic characteristics, nutritional status, treatment used, and time from diagnosis.

\section{Method}

This is a cross-sectional study carried out by telephone interview surveys, with people with diabetes registered in the Diabetics Association of Maringá and Region (Associação dos Diabéticos de Maringá e Região - ADIM). At the time of collection of data there were 3,730 persons aged between 1 and 89 registered in ADIM. For calculation of the sample size, first, only those above the age of 18 and with diagnosis of Type 2 diabetes were considered eligible, resulting in 1,168 
individuals. An estimate was adopted with a confidence interval of 95\% (IC95\%), occurrence of the event of interest of $50 \%$ and maximum error of five percentage points in the level of occurrence of any risk factor, with $10 \%$ added to the result for any losses. This resulted in a sample of 318 individuals.

These individuals were selected randomly from a list of active residential telephone lines, supplied by ADIM. Three attempts were made, on different days and at different times of day, aiming to avoid exclusion of a possible participant on the first try due to his/her not being at home at the time of the call or the line being busy. If it was not possible to hold the interview, the researcher proceeded to the next telephone number in the list, up to three substitutions being allowed.

The telephone interviews were held in January through June 2012, by a team comprising nurses and one physiotherapist, previously trained. Their average duration was 20 minutes, and included presentation of: (i) the investigator, (ii) the objects of the study, (iii) the method (approach by telephone) and (iv) verbal consent. After acceptance, the questions and the related reply alternatives were read, and answers recorded on a printed copy of the data collection instrument. Questions from participants about control of the disease were answered by the interviewers at an appropriate moment - in practice, only after the end of the interview.

For investigation of the chosen variables, a form was prepared containing questions from two instruments: (1) the questionnaire from the Vigitel survey - the 'Program for Vigilance of Risk Factors and Protection for Chronic Illnesses by Telephone Enquiry' - of 2011 ${ }^{13}$; and (2) A questionnaire to determine the factors associated with clinical and metabolic control of diabetes, comprising questions that aimed to obtain the information relating to social-demographic, anthropometric and clinical characteristics, and characteristics of the illness (time of diagnosis and presence/absence of complications) and of treatment.

The data was analyzed by the following categories: social-demographic variables (age, in the ranges 18 to 39,40 to 59,60 to 79 , and 80 or over; marital status, categorized as with or without a partner; and level of schooling - categorized into illiterate, primary, secondary and higher education); nutritional status - self-reported using the Body Mass Index (qualified as appropriate when eutrophic, and inappropriate when overweight or obese - there were no participants classified as underweight); type of drug treatment (use of insulin, use of oral antidiabetics, or both); time from diagnosis, in years, as from the age (self-reported) at which the patient received the diagnosis of diabetes - categorized as from 0 to 5 years, 6 to 10,11 to 20 and over 20; and self-reported complications of diabetes (presence or not of kidney problems, difficulty in vision, and foot lesions that are slow to heal).

Defining complications, participants were asked to indicate complications for which a medical diagnosis which had been made that resulted from the diabetes.

For analysis, the data was first entered on Microsoft Office Excel 2010 spreadsheets, and subsequently transferred to the statistical program IBM SPSS ${ }^{\varpi}$, version 20, for compilation of descriptive data, and association tests between the independent variables and the variables of interest (microvascular complications arising from diabetes, in general, and specifically: nephropathy, retinopathy and/or peripheral neuropathy) through univariate analysis (Pearson's chisquared test). Subsequently, the associations were tested and all the variables that showed a value of $\mathrm{p}<0.20$, by the step wise method, were inserted in a multiple logistic regression model. The Odds Ratio (OR) was used as a measure of association, with confidence interval of $95 \%$, significance level established when $\mathrm{p}<0.05$ for the tests carried out, and level of fit for the model verified using the Hosmer and Lemeshow test.

In relation to the ethical precepts of Resolution 196/96 ${ }^{14}$, the Informed Consent Form was read to the participants of the study by the investigators, and the interviews were started only after verbal consent. The project was approved by the Permanent Committee for Ethics in Research on Human Beings of the State University of Maringá.

\section{Results}

The 318 interviewees had average age of 63.1 years \pm 12.2 (minimum 22 , maximum 89 ); more than half were female $(54.1 \%)$, and had completed primary education $(52.8 \%)$, and the majority had a partner $(73.6 \%)$. In the nutritional state variable, the values were balanced: about half the individuals (50.9\%) had inappropriate BMI. All the respondents used some drug treatment for diabetes; 189 used oral antidiabetics (59.43\%); 46 used insulin (14.46\%), and 59 (18.6\%) used the 
combined treatment. The average time from diagnosis of the illness was 13.9 years, \pm 8.8 ( maximum 50 years, minimum 1 year); and $37.1 \%$ received the diagnosis between 10 and 20 years ago. The occurrence of self-reported complications from diabetes was $53.8 \%$, in the following order of frequency: retinopathy $(42.8 \%)$, peripheral neuropathy (14.5\%) and nephropathy (12.9\%).

Univariate analysis of the social/demographic variables indicated association of the presence of complications only with age group: people aged 80 or over were 6.93 (IC: $1.57-30.56$ ) times more likely to have complications than the next age group (Table 1).

In relation to clinical variables, univariate analysis indicated association with (i) BMI, (ii) use of insulin, (iii) use of insulin associated with oral antidiabetics, and (iv) time of diagnosis. People with inappropriate BMI (overweight/obese) had twice the probability of having complications from diabetes than those with appropriate BMI. Similarly, individuals who used insulin, in isolation or in association with oral antidiabetics, more frequently reported complications from diabetes. And individuals diagnosed more than 20 years ago had a higher than chance proportion of reporting complications (Table 2).

With regard to peripheral vascular complications, reported as peripheral neuropathy, an association was found only with the treatment used: Users of insulin had more than twice the chance $(\mathrm{OR}=1.88$; IC95\% $=1.00-3.52)$ of reporting a complication (Table 2).
In relation to self-reported retinopathy, this factor showed association with the age range variable, intensifying with increasing age; the age range from 60 to 79 gave OR $=1.96$, and IC95\% $=1.21-3.28$; and the range 80 or over gave $\mathrm{OR}=$ 2.54 , and IC95\% $=1.06-6.07$. (Table 3 ).

There was strong association with self-reported retinopathy for inappropriate BMI (OR $=2.53$; IC95 $\%=1.60-4.00)$; the treatment used, represented by the use of insulin $(\mathrm{OR}=2.60$; IC95\% $=1.59-4.09)$; and insulin associated with oral antidiabetics $(\mathrm{OR}=1.80$; IC95\% $=1.00$ 3.11).

Finally, a longer time since diagnosis was associated with a greater chance of an individual reporting retinopathy $(\mathrm{OR}=2.52$; IC95\% $=$ 1.21-5.97) - it was more frequently reported by individuals diagnosed more than 20 years ago.

Vascular complications did not have association with demographic variables. The presence of neuropathy was associated with the marital situation "without partner" (OR $=2.00$; IC95\% = 1.00-1.87); inappropriate $\mathrm{BMI}(\mathrm{OR}=2.29$; IC95\% $=1.14-4.62)$; use of insulin in isolation $(\mathrm{OR}=3.32 ; \mathrm{IC} 95 \%=1.74-6.69) ;$ and insulin associated with oral antidiabetics $(\mathrm{OR}=2.30$; IC95\% $=1.14-4.76)$. A highlight association was that individuals treated with insulin had three times the chance of reporting kidney complications.

For peripheral vascular complications, reported as peripheral neuropathy, an association was found only with the type of treatment used:

Table 1. Univariate analysis of the presence of complications, by social-demographic variable, Maringá, 2012.

\begin{tabular}{|c|c|c|c|c|}
\hline \multirow{2}{*}{ Social-demographic variables } & \multicolumn{4}{|c|}{ Complications of diabetes } \\
\hline & n & $\%$ & $\mathbf{p}^{*}$ & OR $(95 \% \mathrm{CI})$ \\
\hline Gender $(\mathrm{n}=318)$ & & & 0.428 & \\
\hline Male & 75 & 51.4 & & - \\
\hline Female & 96 & 55.8 & & - \\
\hline Age group $(\mathrm{n}=318)$ & & & 0.003 & \\
\hline 18 to 39 & 3 & 18.8 & & - \\
\hline 20 to 59 & 42 & 45.7 & & - \\
\hline 60 to 79 & 110 & 59.8 & & - \\
\hline$>80^{* *}$ & 16 & 61.5 & & \\
\hline Marital situation $(\mathrm{n}=318)$ & & & 0.137 & $6.93(1.57-3.56)$ \\
\hline Without partner & 51 & 60.7 & & - \\
\hline With partner & 120 & 51.3 & & - \\
\hline Schooling $(\mathrm{n}=318)$ & & & 0.374 & \\
\hline Illiterate & 13 & 59.1 & & - \\
\hline Primary education & 83 & 49.5 & & - \\
\hline Secondary education & 41 & 61.2 & & - \\
\hline Higher education & 34 & 55.7 & & - \\
\hline
\end{tabular}


Table 2. Univariate analysis of the presence of complications by clinical variable, Maringá, 2012.

\begin{tabular}{|c|c|c|c|c|}
\hline \multirow{2}{*}{ Clinical variables } & \multicolumn{4}{|c|}{ Complications of diabetes } \\
\hline & $\mathbf{n}$ & $\%$ & $\mathbf{p}^{*}$ & OR (95\% IC) \\
\hline $\mathrm{BMI}(\mathrm{n}=318)$ & & & 0.002 & \\
\hline Appropriate & 70 & 44.9 & & - \\
\hline Inappropriate & 101 & 62.3 & & $2.03(1.30-3.18)$ \\
\hline Treatment used $(\mathrm{n}=318)$ & & & $<0.001$ & \\
\hline Insulin & & & & \\
\hline No & 95 & 44.6 & & - \\
\hline Yes & 76 & 72.4 & & $3.30(1.98-5.34)$ \\
\hline Oral antidiabetics & & & 0.712 & \\
\hline No & 39 & 55.7 & & - \\
\hline Yes & 132 & 52.2 & & - \\
\hline Both & & & 0.003 & \\
\hline No & 129 & 49.8 & & - \\
\hline Yes & 42 & 71.2 & & $2.50(1.36-4.54)$ \\
\hline Years since diagnosis $(\mathrm{n}=291)^{* * *}$ & & & 0.013 & \\
\hline 0 to 5 years & 27 & 43.5 & & - \\
\hline 6 to 10 years & 31 & 46.3 & & - \\
\hline 11 to 20 years & 66 & 55.9 & & - \\
\hline$>20^{* *}$ years & 32 & 72.7 & & $3.45(1.50-7.94)$ \\
\hline
\end{tabular}

"Chi-squared of Pearson; ${ }^{* *}<<0.05 ;{ }^{* * *}$ Did not remember/did not know: 27 respondents.

Table 3. Frequency of self-reported retinopathy, nephropathy and neuropathy, by social-demographic variable, Maringá, 2012.

\begin{tabular}{|c|c|c|c|c|c|c|c|c|c|}
\hline \multirow{2}{*}{ Variables } & \multicolumn{3}{|c|}{ Retinopathy $(n=136)$} & \multicolumn{3}{|c|}{ Nephropathy $(n=41)$} & \multicolumn{3}{|c|}{ Peripheral neuropathy $(n=46)$} \\
\hline & $\mathbf{n}$ & $\%$ & $\mathbf{p}^{*}$ & $\mathbf{n}$ & $\%$ & $\mathrm{p}$ & $\mathbf{n}$ & $\%$ & $\mathbf{p}$ \\
\hline Gender & & & 0.143 & & & 0.343 & & & 0.970 \\
\hline Male & 56 & 38.4 & & 16 & 11.0 & & 21 & 14.4 & \\
\hline Female & 80 & 46.5 & & 25 & 14.5 & & 25 & 14.5 & \\
\hline Age group & & & 0.003 & & & 0.978 & & & 0.472 \\
\hline 18 to 39 & 1 & 6.2 & & 2 & 12.5 & & - & - & \\
\hline 20 to 59 & 33 & 35.9 & & 11 & 12.0 & & 12 & 11.1 & \\
\hline 60 to $79^{* *}$ & 88 & 47.8 & & 25 & 13.6 & & 30 & 16.3 & \\
\hline$>80^{* *}$ & 14 & 53.8 & & 3 & 11.5 & & 4 & 15.4 & \\
\hline Marital situation & & & 0.782 & & & 0.050 & & & 0.677 \\
\hline Without partner & 37 & 42.3 & & 16 & 19.0 & & 11 & 13.1 & \\
\hline With partner & 99 & 44.0 & & 25 & 10.7 & & 35 & 15.0 & \\
\hline Schooling & & & 0.142 & & & 0.327 & & & 0.095 \\
\hline Illiterate & 10 & 45.5 & & 5 & 22.7 & & 4 & 18.2 & \\
\hline Primary & 62 & 36.9 & & 18 & 10.7 & & 31 & 18.5 & \\
\hline Secondary & 32 & 47.8 & & 11 & 16.4 & & 7 & 10.4 & \\
\hline Higher education & 32 & 52.5 & & 7 & 11.5 & & 4 & 6.6 & \\
\hline
\end{tabular}

"Significance according to Pearson chi-squared test. ${ }^{* *} \mathrm{p}<0.05$.

People who used insulin in isolation were almost twice as likely $(\mathrm{OR}=1.88 ; \mathrm{IC} 95 \%=1.00-3.52)$ to report this type of complication (Table 4 ).

Table 5 shows the variables that continued to be associated with the general presence of com- plications and the presence of retinopathy and nephropathy, in the multiple logistic regression, as well as the related adjustment variables.

A higher proportion of complications was found among individuals who used insulin, who 
had inappropriate BMI and who were in the age range 60 to 79; and these variables were not independent of: combined treatment of insulin with oral antidiabetics; nor of time from diagnosis; nor of marital situation.

Reporting of retinopathy was most frequent in individuals with inappropriate BMI and those between age 60 and 79, or 80 and above. However, these associations were not independent from treatment with (a) insulin and (b) time since diagnosis. Higher occurrence of nephropathy was found among individuals who used insulin, had inappropriate BMI and were without a partner, though we consider that the association of these variables was not independent from combined treatment with insulin and oral antidiabetics.

Finally, no associations with peripheral neuropathy were found in the multiple analysis.

Table 4. Frequency of retinopathy, nephropathy and peripheral neuropathy by clinical variable, Maringá, 2012.

\begin{tabular}{|c|c|c|c|c|c|c|c|c|c|}
\hline \multirow{2}{*}{ Clinical variables } & \multicolumn{3}{|c|}{ Retinopathy $(\mathrm{n}=136)$} & \multicolumn{3}{|c|}{ Nephropathy $(n=41)$} & \multicolumn{3}{|c|}{ Peripheral neuropathy $(n=46)$} \\
\hline & $\mathbf{n}$ & $\%$ & $\mathbf{p}^{*}$ & $\mathbf{n}$ & $\%$ & $\mathbf{p}^{*}$ & $\mathbf{n}$ & $\%$ & $\mathbf{p}^{*}$ \\
\hline BMI $(\mathrm{n}=318)$ & & & $<0.001$ & & & 0.017 & & & 0.857 \\
\hline Appropriate & 49 & 31.4 & & 13 & 8.3 & & 22 & 14.1 & \\
\hline Inappropriate & 87 & 53.7 & & 28 & 17.3 & & 24 & 14.8 & \\
\hline Insulin & & & $<0.001$ & & & $<0.001$ & & & 0.049 \\
\hline No & 75 & 35.2 & & 17 & 8.0 & & 25 & 11.7 & \\
\hline Yes & 61 & 58.1 & & 24 & 22.9 & & 21 & 20.0 & \\
\hline Oral antidiabetics & & & 0.402 & & & 0.108 & & & 0.961 \\
\hline No & 33 & 47.1 & & 13 & 18.6 & & 10 & 14.3 & \\
\hline Yes & 103 & 41.5 & & 28 & 11.3 & & 36 & 14.5 & \\
\hline Both & & & 0.048 & & & 0.020 & & & 0.312 \\
\hline No & 104 & 40.2 & & 28 & 10.8 & & 35 & 13.5 & \\
\hline Yes & 32 & 54.2 & & 13 & 22.0 & & 11 & 18.6 & \\
\hline Years since diagnosis ${ }^{* * *}$ & & & 0.024 & & & 0.240 & & & 0.099 \\
\hline 0 to 5 & 23 & 37.1 & & 3 & 4.8 & & 5 & 8.1 & \\
\hline 6 to 10 & 23 & 34.3 & & 10 & 14.9 & & 6 & 9.0 & \\
\hline 11 to 20 & 55 & 46.6 & & 17 & 14.4 & & 23 & 19.5 & \\
\hline$>20^{*}$ & 27 & 61.4 & & 5 & 11.4 & & 7 & 15.9 & \\
\hline
\end{tabular}

"Significance according to Person chi-squared test. ${ }^{* *} \mathrm{p}<0.05 .{ }^{* * *}$ Retinopathy $(\mathrm{n}=128)$, nephropathy $(\mathrm{n}=35)$, peripheral neuropathy $(\mathrm{n}=41)$.

Table 5. Factors associated with complications of diabetes (presence, retinopathy and nephropathy), according to multiple logistic regression models: people with diabetes answering survey by telephone, Maringá, Parana, Brazil, 2013.

\begin{tabular}{lcc}
\multicolumn{1}{c}{ Independent variables } & \multicolumn{2}{c}{ Complications from diabetes } \\
\cline { 2 - 3 } & OR $(\mathbf{9 5 \%} \mathbf{C I})$ & Value $\mathbf{p}$ \\
\hline Presence of complications* $^{*}$ & & \\
$\quad$ Insulin (yes) & $2.64(1.20-5.78)$ & 0.016 \\
BMI (inappropriate) & $2.30(1.36-3.86)$ & 0.002 \\
Age range (60 to 79) & $7.00(1.39-35.28)$ & 0.018 \\
Retinopathy & & \\
BMI (inappropriate) & $2.82(1.68-4.73)$ & $<0.001$ \\
Age range (60 to 79) & $9.97(1.18-83.95)$ & 0.034 \\
Age range (80 and over) & $12.42(1.26-121.85)$ & 0.031 \\
Nephropathy & & \\
Insulin (Yes) & $3.65(1.54-8.63)$ & 0.003 \\
BMI (inappropriate) & $2.50(1.19-5.23)$ & 0.015 \\
Marital situation (without partner) & $2.28(1.10-4.73)$ & 0.026 \\
\hline
\end{tabular}

"Model adjusted for the variables 'Treatment with insulin and oral and oral antidiabetics', 'Time since diagnosis' and 'Marital situation'. ${ }^{* *}$ Model adjusted for the variables 'use of insulin' and 'time since diagnosis'. ${ }^{* * *}$ Model adjusted for the variable 'treatment with insulin and oral antidiabetics'. 


\section{Discussion}

The chronic complications of DM2 have become increasingly common as more people, gradually, have developed this metabolic disorder ${ }^{15}$. The occurrence of microvascular complications found in this study is high (53.8\%), compared to that identified in a prospective study (57 months) made with 471 patients with diabetes and age and gender similar to those of this present study, in which it was found that $41.6 \%$ developed microvascular complications ${ }^{16}$. The higher occurrence found in this present study, thus, may be related to the fact that the individuals of the other study were monitored through an outpatient facility, whereas in this study, (1) a peculiar method of data collection (telephone interview) having been adopted, which does not guarantee precision of data (since the data received depends on memory, or may be the result of misunderstanding of information received from health professionals, or might be affected by a degree of willingness to reveal complete information), and (2) the respondents came from a registry of an Association, without any information relating to the monitoring of their health.

Looking at the complications in isolation, it stands out that the occurrence found for diabetic retinopathy $(42.8 \%)$ was higher than that found in a study carried out on 168 patients with DM2 in the western population of India, which showed occurrence of $33.9 \%$; ; on the other hand it was lower than the level found in a study carried out in Porto Alegre, Brazil, with people with average age of $53(48.6 \%)$ - that is to say, younger than those interviewed in this present study ${ }^{17}$. The association identified between retinopathy and time since diagnosis corroborates the finding of the study carried out in India, in which retinopathy was found to arise 11 years after diagnosis ${ }^{18}$. The same is true of people with Type 1 diabetes mellitus - a study in the United Kingdom reported that after 11 years from diagnosis the occurrence of some degree of retinopathy is around $66.6 \%$, rising to approximately $100 \%$ after 20 years ${ }^{19}$.

Indeed, time of progression of DM2 can determine a greater risk for development of microvascular complications in general. A study of a retrospective cohort made in Australia, for example, compared the repercussions of early start of diabetes and found that Type 2 is the phenotype that represents greater concern, due to the association with micro- and macrovascular complications, cardiovascular illnesses and early death from cardiovascular causes ${ }^{20}$.
In the present study, diabetic nephropathy was in third place in terms of frequency of occurrence, which differed from the study made in Porto Alegre ${ }^{10}$ where it was the second most frequent, representing $34.5 \%$ of microvascular complications. However, a study made with adults attended in the endocrinology outpatients area of a General Hospital of the Brazilian state of Ceará ${ }^{5}$ found the most frequent complication to be peripheral neuropathy (41.1\%), followed by nephropathy $(28.2 \%)$ and retinopathy $(16.4 \%)$. The differences found may be attributed to the way in which the data were collected, since in the studies referred to, the information was obtained from medical records, whereas self-reported information was used in this present study.

Also, it is important to take into account that cultural differences can also be reflected in the occurrence of complications found in different locations. For example, a survey made in four large Chinese cities with 1,524 adult patients with diabetes found complications in $34.7 \%{ }^{21}$, in the same order as in this present study, but with different values: $14.8 \%$ for retinopathy, $10.7 \%$ for peripheral neuropathy and $0.8 \%$ for nephropathy.

Retinopathy, also, was the complication most reported in two studies made in the municipalities of Campinas and Botucatu, cities in the state of São Paulo, Brazil, in which retinopathy was found in $29 \%$, and $40 \%$, of the cases of diabetes, respectively ${ }^{12}$. It should be pointed out that although nephropathy is the least frequent complication, it is one of the principal causes of increases of dialysis and mortality in people with DM2 $2^{13,22}$, representing, in many countries, one of the principal causes of the final stage of kidney disease $^{23}$.

Thus, considering the complexity of diabetic nephropathy, its prevention and treatment require multifactorial intervention, involving the control of high blood pressure, hypoglycemia, dyslipidemia, use of tobacco, nephrotoxins, and the use of nephroprotection agents and changes in lifestyle, contributing to retarding the progress of a kidney lesion and reducing the risk of cardiovascular disease and/or death from cardiovascular events ${ }^{22}$.

From the clinical point of view the diagnosis of DM2, by itself, already confers an increase in the risk of developing circulatory events, leading, in some cases, to peripheral neuropathy, which is the most important factor related to the development of ulcers. It is already present in $8 \%$ of patients at the time of diagnosis, in 15\% after 10 years and in $42 \%$ after 20 years $^{22}$. It is a compli- 
cation that constitutes the cause of between 50\% and $70 \%$ of non-traumatic amputations, and $50 \%$ of hospital admissions for diabetes ${ }^{24}$.

The association that was found between the presence of complications and the higher age groups corroborates findings of population-based surveys ${ }^{8,25}$. This association is certainly related to the greater occurrence of the pathology in older individuals, according to a study made in Ceará, which found predominance of the disease in people over the age of $60^{26}$. Also, physiopathological processes inherent in aging such as, for example, atherosclerosis, hyperopia, immunological alterations, may compromise the capacity for scar healing, which can increase the occurrence of complication $\mathrm{s}^{27}$. Older people, thus, have probably been aware of the diagnosis of the disease for a longer time and, consequently, are more exposed to its complications, since, although the factor 'time from diagnosis' was not shown by this study to be associated with complications, it participated in the multiple models found in the study as an adjustment factor, indicating the relationship of dependency with the associated variables.

In the present study, the only risk factor that was modifiable was the altered body mass index. Recent WHO data show that being overweight, and obese, are among the five principal risk factors for DM2, with an important impact on the global occurrence of the disease. Thus, frequently the reduction and control of weight is one of the principal strategies for non-pharmacological treatment of the illness ${ }^{28}$. Thus, loss of between $5 \%$ and $10 \%$ of body weight is already able to reduce glycemic levels, retarding the progression of the disease, reducing the risk of complications and even leading to suspension of pharmacological treatment ${ }^{12}$. In view of this, it is necessary to emphasize the need for multi-professional interventions that aim for diet re-education, daily practice of physical activity, prevention with a view to control of weight, and acquisition of healthy life habits ${ }^{29}$.

In relation to pharmacological treatment, a significant association was found between the use of insulin and the occurrence of microvascular complications of DM2, and it was also the only variable associated with neuropathy. This association needs to be considered, since the use of insulin has been related to better glycemic control which, in turn, has been associated with lower frequency of complication from the disease, but the need for introduction of exogenous insulin constitutes an indication that the organism is not succeeding in maintaining gly- cemic control, resulting in a constant increase in intracellular glucose $\mathrm{e}^{30}$.

Continuation of this lack of glycemic control leads to oxidative stress and endothelial dysfunction - events that are precursors of tissue damage, and are determinant for the development of micro and macrovascular complications. Both are common denominators through which hyperglycemia, arterial hypertension and dyslipidemia act in the generation of these complications. Thus, the persistence of these alterations can be responsible for the mechanism of metabolic memory, related to the emergence of complications, even in individuals who use exogenous insulin ${ }^{30}$.

Also, it needs to be noted that insulin-dependent individuals are more predisposed to the occurrence of microalbuminuria, which precedes the emergence of diabetic nephropathy ${ }^{31}$. It can also be one of the markers for endothelial dysfunction, characteristic of the presence of oxidative stress and future tissue lesion. It also needs to be considered that individuals can use insulin improperly, that is to say, without following the medical prescription, or even use it to compensate for sporadic dietary extravagances ${ }^{32}$.

In relation to time since diagnosis, studies have shown its influence on the occurrence of complications associated with diabetes ${ }^{5,11}$, as also identified in this study. Taking only retinopathy as an example, it is estimated that after 15 years from diagnosis of DM2, $80 \%$ of patients have some degree of lesion in the retina ${ }^{33}$, and after 20 years it can be present in $60 \%$ of cases $^{34}$.

It can also be noted that, often, people neglect to take the proper care of the disease, especially those who tend not to recognize its seriousness. This can happen due to lack of motivation, due to disbelief in the seriousness of the disease, or in the benefits that certain actions can provide for its control. Also, the patient's motivation and attitudes as to the treatment are not stable, and much less, indeed, crystalized, but subject to a pre-disposition toward adoption of self-treatment actions, influenced by cognitive, motivational and emotional components - and they may, also, be stimulated by health profession$\mathrm{als}^{32,35}$. Periods of greater or lesser adherence to the care are part of the process of confronting the illness. In view of this, studies have emphasized the need for health professionals constantly to evaluate the risk for complications and their presence and, through educational and motivational activities, to improve self-treatment and the maintenance of glycemic control ${ }^{15}$. 
As an overall conclusion, the risk factors for complications identified in this study were: age above 80; time since diagnosis of the disease; use of insulin; and altered body mass index - the first three not being modifiable, and only the last being subject to modification as a result of the activity of health professionals. Health professionals, in turn, need to find means for their activity to result in effective changes in lifestyle, and, more strongly, in the control and reduction of weight in people with DM2.

The offer of educational interventions by the health services, and the participation of people with diabetes in groups that deal with information about the disease, types of conduct for loss of body weight, and healthy life habits, can favor the awareness and development of skills for daily self-care that the disease demands ${ }^{12}$. Thus, to improve the care for people with DM2, it is essential to combine the actions of prevention with those of control and treatment of the complica- tions, with a view to diminishing the disease, and mortality resulting from it, since this group has three times higher mortality than the population in general ${ }^{36}$.

It can be emphasized that one of the methodological limitations of this present study is the use of self-reported data, and, above all, the fact that it was carried out on individuals registered in a single association of people with diabetes, which makes it impossible to generalize from the data, or to make possible inferences for other scenarios, such as, for example, the public health services.

However, in view of its economic and technical feasibility, use of telephone interviews is recommended, not only as a method for data collection in surveys, but also as a strategy for monitoring the health conditions of individuals with DM2 in the public health services, especially those who have risk of complications, or, indeed, when these complications already exist.

\section{Contributors}

AL Santos, HPM Cecílio, EF Teston, GO Arruda, FMN Paternela and SS Marcon contributed to the conception and development of the survey, analysis and interpretation of the data, significant critical review of the intellectual content, and approval of the final version to be published.

\section{References}

1. Karino MA, Pace AE. Risco para complicações em pés de trabalhadores portadores de diabetes mellitus. Cien Cuid Saude 2012; 11(Supl.):183-190.

2. Oliveira PPl. Análise comparativa do risco de quedas entre pacientes com e sem diabetes melittus tipo 2. Rev Assoc Med Bras 2012; 58(2):234-239.

3. Freitas LRS, Garcia LP. Evolution of prevalence of diabetes and associated hypertension in Brazil: analysis of National Household Sample Survey, 1998, 2003 and 2008. Epidemiol Serv Saúde 2012; 21(1):7-19.

4. Mazzini MCR, Blumer MG, HoehneEL, Guimarães KRLSLQ, Caramelli B, Fornari L, Malheiros SVP. Rastreamento do risco de desenvolvimento de diabetes mellitus em pais de estudantes de uma escola privada na cidade de Jundiaí, São Paulo. Rev Assoc Med Bras 2013; 59(2):136-142.

5. Queiroz PC, Aguiar DC, Pinheiro RP, Moraes CC, Pimentel IRS, Ferraz CLH, Ferraz TMBL. Prevalência das complicações micro e macrovasculares e de seus fatores de risco em pacientes com diabetes mellitus e síndrome metabólica. Rev Soc Bras Clin Med 2011; 9(4):254-258. 
6. Cenci DR, Silva MD, Gomes EB, Pinheiro HA. Análise do equilíbrio em pacientes diabéticos por meio do sistema F-Scan e da Escala de Equilíbrio de Berg. Fisiot Mov 2013; 26(1):55-61.

7. Oliveira AF, Valente JG, Leite IC, Schramm JMA, Azevedo AR, Gadelha AMJ. Global Burden oh disease attributable to diabetes mellitus in Brazil. Cad Saude Publica 2009; 25(6):1234-1244.

8. Santos JC, Moreira TMM. Fatores de risco e complicações em hipertensos/diabéticos de uma regional sanitária do nordeste brasileiro. Rev Esc Enferm 2012, 46(5):1125-1132.

9. Caiafa JS, Castro AA, Fidelis C, Santos VP, Silva ES, Sitrângulo CJ. Atenção integral ao portador de Pé Diabético. J Vasc Bras 2011; 10(4):11-32.

10. Rodrigues TC, Pecis M, Canani LH, Schreiner L, Kramer CK, Biavatti K, Macedo B, Esteves JF, Azevedo MJ. Caracterização de pacientes com diabetes mellitus tipo 1 do sul do Brasil: complicações crônicas e fatores associados. Rev Assoc Med Bras 2010; 56(1):67-73.

11. Rodrigues DF, Brito GEG, Sousa NM, Rufino TMS, Carvalho TD. Prevalência de Fatores de Risco e Complicações do Diabetes Mellitus Tipo 2 em Usuários de uma Unidade de Saúde da Família. Rev Bras Cien Saúde 2011; 15(3):277-228.

12. Torres HC, Reis IA, Roque C, Faria P. Monitoramento telefônico como estratégia educativa para o autocuidado das pessoas com diabetes na Atenção Primária. Cienc y Enferm 2013, 19(1):95-105.

13. Brasil. Ministério da Saúde (MS). Secretaria de Vigilância em Saúde. Secretaria de Gestão Estratégica e Participativa. Vigitel Brasil 2011: vigilância de fatores de risco e proteção para doenças crônicas por inquérito telefônico. Brasília: MS; 2012.

14. Brasil. Ministério da Saúde (MS). Conselho Nacional de Saúde. Resolução nº 196 de 10 de outubro de 1996. Diretrizes e Normas Regulamentadoras de Pesquisas Envolvendo Seres Humanos. Diário Oficial da União 1996; 16 out.

15. Francisco PMSB, Belon AP, Barros MBA, Carandina L, Alves MCGP, Goldbaum M, César CLG. Diabetes auto-referido em idosos: prevalência, fatores associados e práticas de controle. Cad Saude Publica 2012; 26(1):175-184.

16. Cardoso CR, Salles GF. Predictors of development and progression of microvascular complications in a cohort of Brazilian type 2 diabetic patients. J Diabetes Complications 2008; 22(3):164-170.

17. Mielczarski RG, Costa JSD, Olinto MTA. Epidemiologia e organização de serviços de saúde: diabetes mellitus numa comunidade de Porto Alegre. Cien Saude Colet 2012; 17(1):71-78.

18. Ramavat PR, Ramavat MR, Ghugare BW, Vaishnav RG, Joshi MU. Prevalence of Diabetic Retinopathy in Western Indian Type 2 Diabetic Population: A Hospital based Cross - Sectional Study. J Clin Diagn Res 2013; 7(7):1387-1390.

19. Bryden KS, Dunger DB, Mayou RA, Peveler RC, Neil HA. Poor Prognosis of young adults with type 1 Diabetes. Diabetes Care 2003; 26(4):1052-1057.

20. Constantino MI. Long-term complications and mortality in Young-onset diabetes: type 2 diabetes is more hezardous and lethal than type 1 diabetes. Diabetes Care 2013. 36(12):3863-3869.

21. Liu Z, Fu C, Wang W, Xu P. Prevalence of chronic complications of type 2 diabetes mellitus in outpatients - a cross-sectional hospital based survey in urban China. Health and Quality of Life Outcomes 2010; 8:62.
22. Viana MR, Rodriguez TT. Complicações cardiovasculares e renais no diabetes mellitus. Rev Cien Med Biol 2011; 13(3):290-296.

23. Wolf G, Busch M, Müller N, Müller UA. Association between socioeconomic status and renal function in a population of German patients with diabetic nephropathy treated at a tertiary centre. Nephrol Dial Transplant 2011; 26(12):4017-4023.

24. Araujo MM, Alencar AMPG. Pés de risco para o desenvolvimento de ulcerações e amputações em diabéticos. Rev Rene 2009; 10(2):19-28.

25. Demakakos P, Hamer M, Stamatakis E, Steptoe A. Low -intensity physical activity is associated with reduced risk of incident type 2 diabetes in older adults: evidence from the English Longitudinal Study of Ageing. Diabetologia 2010; 53(9):1877-1885.

26. Araújo MFM, Gonçalves TC, Damasceno MMC, Caetano JA, Aderência de diabéticos ao tratamento medicamentoso com hipoglicemiantes orais. Rev Anna Nery 2010; 14(2):361-367.

27. Meireles AE, Pereira LMS, Oliveira TG, Christofoletti G, Fonseca Al. Alterações neurológicas fisiológicas ao envelhecimento afetam o sistema mantenedor do equilíbrio. Rev Neurocienc 2010; 18(1):103-108.

28. World Health Organization (WHO). Global health risks: mortality and burden of disease attributable to selected major risks. Genebra: WHO; 2009.

29. Azevedo ECC, Dias FMRS, Diniz AS, Cabaral PC. Consumo alimentar de risco e proteção para as doenças crônicas não transmissíveis e sua associação com a gordura corporal: um estudo com funcionários da área de saúde de uma universidade pública de Recife (PE),

30. Brasil. Cien Saude Colet 2014; 19(5):1613-1622. Oliveira JEP, Vencio S, organizadores. Diretrizes da Sociedade Brasileira de Diabetes: 2013-2014. São Paulo: AC Farmacêutica; 2014.

31. Al-Agha AE, Ocheltree A, Hakeem A. Occurrence of microalbuminuria among children and adolescents with insulin-dependent diabetes mellitus. Saudi J Kidney Dis Transpl 2013; 24(6):1180-1188.

32. Santos AL, Marcon SS. How people with diabetes evaluate participation of their family in their health care? Invest Educ Enferm 2014; 32(2):260-269.

33. Dias AFG, Vieira MF, Rezende MP, Oshima A, Muller MEW, Santos MEX, Serracarbassa PD. Perfil epidemiológico e nível de conhecimento de pacientes diabéticos sobre diabetes e retinopatia diabética. Arq Bras Oftalmol 2010; 73(5):414-418.

34. Carpena MP, Rados DV, Sortica DA, Souza BM, Reis AF, Canani LH, Crispim D. Genetics of diabetic nephropathy. Arq Bras Endocrinol Metab 2010; 54(3):253-261.

35. Rodrigues FFL, Santos MA, Teixeira CRS, Gonela JT, Zanetti ML. Relationship between knowledge, attitude, education and duration of disease in individuals with diabetes mellitus. Acta Paul Enferm 2012; 25(2):284290.

36. Milioli R, Vargas MAO, Leal SMS, Montiel AA. Qualidade de vida em pacientes submetidos a amputação. Rev Enferm UFSM 2012; 2(2):311-319.

Article submitted on 20/08/2014

Approved on 24/08/2014

Final version submitted on 26/08/2014 